University of Wollongong

Research Online

Australian Institute for Innovative Materials -

Papers

Australian Institute for Innovative Materials

$1-1-2015$

Improving fault ride-through capability of DFIG based wind generators by using bridge-type superconducting fault current limiter

\author{
Mehrdad Tarafdar Hagh \\ University of Wollongong, mehrdadh@uow.edu.au \\ Kashem M. Muttaqi \\ University of Wollongong, kashem@uow.edu.au \\ Danny Sutanto \\ University of Wollongong, soetanto@uow.edu.au \\ Md Shahriar Hossain \\ University of Wollongong, shahriar@uow.edu.au \\ Ahmed M. Haidar \\ University of Wollongong, ahaidar67@hotmail.com
}

Follow this and additional works at: https://ro.uow.edu.au/aiimpapers

Part of the Engineering Commons, and the Physical Sciences and Mathematics Commons 


\title{
Improving fault ride-through capability of DFIG based wind generators by using bridge-type superconducting fault current limiter
}

\author{
Abstract \\ This paper proposes series connection of a diode bridge-type superconducting fault current limiter (SFCL) \\ with rotor side converter (RSC) of a double fed induction generator (DFIG) based wind turbine. The \\ proposed SFCL improves the fault ride through (FRT) capability of DFIG and prevents the RSC from \\ damaging fault currents. Because of using superconductor DC coil, there is not any power loss during \\ fault or normal operation of system. The proposed SFCL does not have any considerable affect in wind \\ turbine's operation during normal condition. It is not necessary to use any measurement and control \\ systems, too. The SFCL returns to its normal operation after fault clearing in a very short time without any \\ switching device. The modeling of proposed SFCL is presented based on analytical analysis. Simulation \\ of a 2 MW 690 V DFIG with and without using the proposed SFCL is carried out by PSCAD/EMTDC \\ software. The results show the excellent operation of proposed SFCL in improving the FRT of DFIG based \\ wind turbine.

\section{Keywords} \\ current, superconducting, type, bridge, generators, wind, dfig, capability, limiter, ride, improving, fault

\section{Disciplines} \\ Engineering | Physical Sciences and Mathematics

\section{Publication Details} \\ Hagh, M. Tarafdar., Muttaqi, K. M., Sutanto, D., Hossain, M. S. A. \& Haidar, A. M. A. (2015). Improving fault \\ ride-through capability of DFIG based wind generators by using bridge-type superconducting fault current \\ limiter. Power Engineering Conference (UPEC), 2015 50th International Universities (pp. 1-6). United \\ States: Institute of Electrical and Electronics Engineers.
}




\title{
Improving Fault Ride-through Capability of DFIG based Wind Generators by Using Bridge-Type Superconducting Fault Current Limiter
}

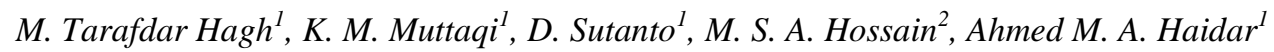 \\ ${ }^{1}$ Australian Power Quality and Reliability Centre, School of Electrical, Computer and Telecommunications Engineering \\ ${ }^{2}$ Institute for Superconducting and Electronic Materials, Australian Institute for Innovative Materials \\ University of Wollongong, Wollongong, Australia \\ mehrdadh@uow.edu.au,kashem@uow.edu.au,soetanto@uow.edu.au,shahriar@uow.edu.au,ahaidar@uow.edu.au
}

\begin{abstract}
This paper proposes series connection of a diode bridge-type superconducting fault current limiter (SFCL) with rotor side converter (RSC) of a double fed induction generator (DFIG) based wind turbine. The proposed SFCL improves the fault ride through (FRT) capability of DFIG and prevents the RSC from damaging fault currents. Because of using superconductor DC coil, there is not any power loss during fault or normal operation of system. The proposed SFCL does not have any considerable affect in wind turbine's operation during normal condition. It is not necessary to use any measurement and control systems, too. The SFCL returns to its normal operation after fault clearing in a very short time without any switching device. The modeling of proposed SFCL is presented based on analytical analysis. Simulation of a 2 MW 690 V DFIG with and without using the proposed SFCL is carried out by PSCAD/EMTDC software. The results show the excellent operation of proposed SFCL in improving the FRT of DFIG based wind turbine.
\end{abstract}

Index Terms - Bridge type fault current limiter; Doubly-fed induction generator; Fault Ride Through; Superconductor; Wind generator

\section{INTRODUCTION}

The use of renewable energy sources either as distributed generators (DGs) in public AC networks or as isolated generating units has attracted a great deal of attention during last decades. Among different kinds of renewable energy sources, wind power and solar photovoltaic have been the most emerging and still more efficient and attractive power sources for the future. According to European Wind Energy Association (EWEA), wind will contribute up to $230 \mathrm{GW}$ $260 \mathrm{GW}$ by 2020 in Europe and total wind power generation in Europe would be $400 \mathrm{GW}$ by 2030 .

While the penetration of wind energy is rapidly increasing worldwide, improving the Fault Ride Through (FRT) capability of wind turbines has become an important issue of research. Wind turbine manufacturers and power utilities are looking for innovation in technology development in this area. High penetration of wind turbines in power system has made it necessary to review the existing grid codes requirements [1]-[7]. Grid codes in Europe and most other countries require wind turbines to stay connected to utility systems during fault conditions for a stipulated period of time. On the other hand, wind turbines experience considerable electrical and mechanical stress during the faults. One of the key elements which could be utilized successfully for improving the FRT capability of wind turbines is FCL.

Whereas the non-superconductor type FCLs have their own advantages such as elimination of cryostat system and low cost, volume, weight and technology, superconducting FCLs have got considerable attention due to their no power loss performance [8]-[12].

Reference [13] has proposed application of a solid state SFCL that is connected between an induction generator based wind turbine and utility for fault ride through improvement purpose. The paper has used a solid state switch which turns off during fault condition and inserts an impedance in series with wind turbine. The paper has compared the performance of a resistive type impedance (R-type) with an inductive type (L-type) impedance and proposes the combination of R-type and L-type impedances. The paper has proved the excellent performance of proposed FCL.

In [14] application of a dynamic voltage restorer (DVR) as a FCL is investigated for FRT improvement of a DFIG. The DVR is connected in series with wind turbine. The valuable operation of DVR is approved through analytical and simulation results.

Recently, the application of bridge-type FCLs in wind turbines has attracted the attention of researchers. In [15] a bridge type FCL is proposed that is connected in series with protected transmission line. A modified bridge-type FCL is proposed in [16] for fixed speed wind generator that contains a semiconductor switch and is connected in series with protected transmission line. The state of switch changes from on to off in fault instant to insert an impedance in series with fault. In [17] a circuit arrangement, based on using a bridge type SFCL is proposed in which its FCL inductor could be utilized as energy storage in normal condition.

This paper has introduced a new application of bridge-type FCL for FRT improvement of DFIG based wind turbines. The proposed FCL is connected inside the DFIG power circuit rather than connecting on its terminal. The proposed topology has not any considerable effect on operation of wind turbine in normal condition. During fault condition, the FCL 
poses itself as a series inductor between rotor of DFIG and rotor side converter (RSC) and improves the FRT capability of wind turbine.

This paper is organized as follows:

Section II and III explain the analytical analysis of induced voltages in rotor of a DFIG in normal and fault conditions, respectively. The proposed power circuit topology is introduced in section IV. Section V explains power circuit modeling and related analysis. Section VI presents the simulation results. Section VII is the conclusion of paper that is followed by references.

\section{ROTOR VOLTAGE OF DFIG IN NORMAL CONDITION}

DFIG based wind turbine is one of the most popular types of wind turbines. The main electrical parts of a DFIG wind turbine consists of a DFIG, RSC, DC bus and grid side converter (GSC). In the static stator-oriented reference frame, the model of the DFIG can be expressed as follows by using the Clark transformation [18]:

$$
\begin{aligned}
& V_{s}=R_{S} I_{s}+d \psi_{s} / d t \\
& V_{r}=R_{r} I_{r}+d \psi_{r} / d t+j \omega_{r} \psi_{r} \\
& \psi_{s}=L_{S} I_{s}+L_{M} I_{r} \\
& \psi_{r}=L_{r} I_{r}+L_{M} I_{S}
\end{aligned}
$$

Where,

$V, I$ are voltage and current phasors, respectively,

$R$ and $L$ stands for the resistance and inductance,

$\psi$ is the magnetic flux phasor,

$\omega_{r}$ is the rotor electrical speed,

$L_{m}$ is the magnetizing inductance.

In the above equations, the subscripts "s" and " $\mathrm{r}$ " indicate stator and rotor quantities. Theses equations are obtained by referring the rotor variables to the stator side. Also, it is supposed that the magnetic circuits are linear.

The phasors in the equations (1) to (4) can be expressed with complex variables in two-phase static reference frame, so, we may write:

$$
V_{s}=V_{s \alpha}+j V_{s \beta}
$$

Where, the subscripts $\alpha$ and $\beta$ represent the variables on perpendicular $\alpha$ and $\beta$ axis, respectively.

Whereas the stator voltage $V_{s}$, of DFIG is same as the grid voltage, the rotor voltage $V_{r}$ is controlled by the RSC. The rotor voltage can also be expressed with the stator flux and rotor current in the rotor frame as follows:

$V_{r}=v_{r r 0}+\left(R_{r} i_{r r}+\sigma L_{r} d i_{r r} / d t\right)$

where, $v_{r r 0}$ is the EMF induced by the stator-flux and we have:

$$
v_{r r 0}=\left(L_{m} / L_{s}\right) \quad\left(d \psi_{r s} / d t\right)
$$$$
\sigma=1-\left(L_{m}^{2} /\left(L_{s} \cdot L_{r}\right)\right) \text {. }
$$

From (6), the equivalent circuit of the DFIG from the rotor point of view can be obtained as shown in Fig. 1. Controlling the rotor currents in normal operation conditions requires that the generated voltage by the RSC be more than the induced EMF to dominate it.

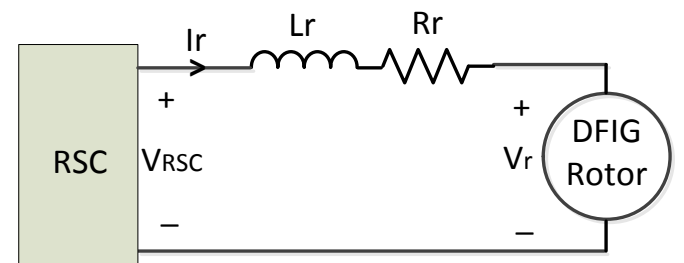

Fig. 1. Equivalent circuit of DFIG from rotor view

\section{RotoR VOLTAGE OF DFIG IN ASYMMETRICAL FAULT CONDITION}

During the fault in utility, stator of DFIG that is connected directly to the grid experiences a voltage dip at its point of common coupling (PCC) to the utility. The stator voltage can be subdivided into the positive, negative and zero sequences. Because of wye-delta connection of DFIG transformer, the zero sequence of voltage could not generate any current towards stator; so we omit the zero sequence voltage in fault analysis. The stator voltage after fault can be expressed as follows [19]:

$V_{S}=V_{S}^{P}+V_{s}^{N}=V_{s}{ }^{P} e^{j \omega t}+V_{S} 0^{N} e^{-j \omega t}$

Where,

$V_{s}{ }^{P}$ stands for the positive component of $V s$ voltage phasor, $V_{s}{ }^{P}$ is the magnitude of $V_{S}{ }^{P}$,

$V_{s}^{N}$ stands for the negative component of $V s$ voltage phasor, $V_{s O}{ }^{N}$ is the magnitude of $V_{s}^{N}$,

$\omega$ is stator angular frequency.

The positive and negative sequences of stator voltages induce related positive and negative sequence of stator flux linkages. Also, change of stator voltage results in DC component of stator flux linkage; so, we have:

$\psi_{s}=\psi_{s}^{P}+\psi_{s}^{N}+\psi_{s}^{O}$

Where, $\psi_{s}^{P}, \psi_{s}^{N}$ and $\psi_{s}{ }^{0}$ stand for positive, negative and zero sequence of stator flux linkage, respectively. Each flux component induces related voltages in rotor winding; so, we have:

$V_{r}=V_{r}^{P}+V_{r}^{N}+V_{r}^{0}$

Where, $V_{r}^{P}, V_{r}^{N}$ and $V_{r}^{0}$ stand for positive, negative and zero sequence of induced voltage in rotor, respectively. 
The frequency of positive and negative sequences are $s \omega$ and $(2-s) \omega$, respectively, where $s$ stands for rotor slip. The magnitude of positive component of rotor voltage $V_{r}^{P}$ depends on the depth of positive sequence of voltage dip and the slip value $s$. Also, the magnitude of negative component of rotor voltage $V_{r}^{N}$ depends on the value of negative sequence of voltage dip and (2-s) [18].

\section{PROPOSED POWER CIRCUIT TOPOLOGY}

Fig. 2 shows the proposed power circuit topology. This circuit consists of a DFIG based wind turbine that is equipped with the proposed diode bridge type SFCL. A three-phase diode-bridge is connected in series with RSC through a series transformer. A superconducting coil is connected in the DC side of the diode-bridge. During the normal operation of wind turbine, the DC coil charges to a DC current and operates like a short circuit. In this condition, the proposed SFCL has not any considerable effect on DFIG operation. During fault condition, as mentioned earlier, the rotor side current tends to increase rapidly. Because, the rotor current is rectified and has to pass through the DC coil, the inductance of DC coil limits its rapid increase. In this way, the FCL protects the RSC, effectively.

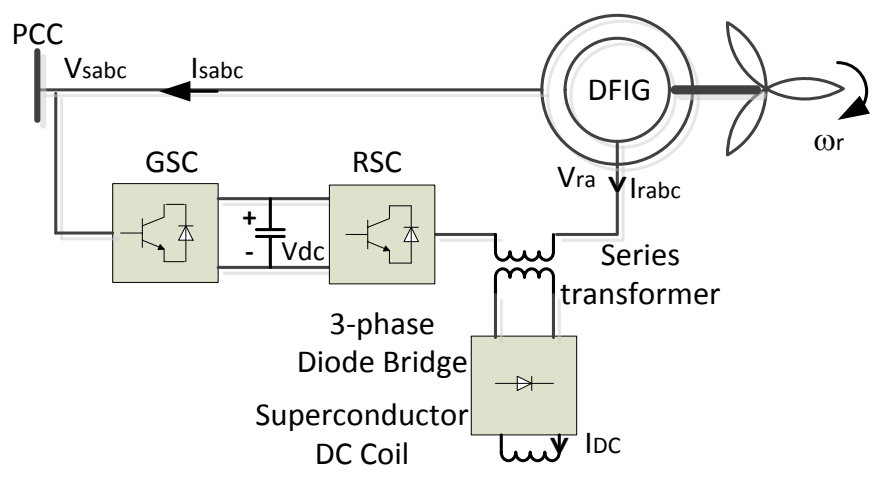

Fig. 2. The proposed power circuit topology

\section{CiRCuit Modelling AND ANALYSIS}

The stator voltage dip during fault condition increases the stator current of DFIG. This increased current induces high currents in the circuit of rotor. In this condition, a transient EMF component, including a declining homogeneous and a steady nonhomogeneous part are induced in the rotor windings. The RSC should provide a suitable voltage difference across the inductor to counteract the nonhomogeneous EMF. The problem is, during fault condition, the induced EMF is usually much larger than the maximum output voltage of RSC, so RSC lose its capability to control the rotor current due to its limited output voltage. On the other hand, the induced high value of EMF could result in damaging current toward the RSC. Increasing the value of inductance between induced EMF and output voltage of RSC could limit this damaging current and improve the controllability of RSC. Indeed, increasing the mentioned inductor could help two basic problems of DFIG during fault conditions which are, runaway of the control system and overcurrent of RSC.

Fig. 3 shows the single-phase modelling of proposed diode bridge SFCL that is inserted in equivalent circuit of the DFIG view from the rotor frame.

During normal condition, the induced voltage in rotor $V_{r}$ is considered to be a steady state sinusoidal voltage for a constant slip value $s$. According to the discussion of section II, the sinusoidal pulse width modulated (SPWM) which RSC generates could be considered as a pure sinusoidal voltage waveform. The mentioned SPWM can be supposed to be a steady state sinusoidal voltage with same frequency of induced voltage in rotor windings but with higher magnitude. The diode-bridge of proposed SFCL rectifies the rotor current. By choosing appropriate value for inductance of DC reactor $L d c$, it is possible to achieve an almost DC current through the DC reactor. Obviously, increasing the inductance of $L d c$, decreases the ripple of DC currents, $I_{D C}$. This leads to short circuit of $L d c$ during normal system operation. There is a forward voltage drop across rectifier diodes $u_{D F}$, but it is small and could be ignored. In this way, the proposed SFCL has not any considerable effect in DFIG operation during normal condition. Now, as Fig. 3 shows, it is possible to sum up two series sinusoidal voltage sources for getting the rotor current phasor $I_{r}$ as follows:

$$
V_{R S C}-V_{r}=R_{r} I_{r}+j L_{r} \omega I r
$$

Where, $V_{R S C}$ stands for phasor representation of generated SPWM waveform by RSC. The sinusoidal rotor current rectifies by diode bridge and charges the superconductor DC reactor to its peak value.

During fault condition, the fault current passes through DC reactor that was already charges to a DC current. To simplify the analysis and by taking the short fault time into account, it is possible to suppose that the generated voltage by RSC doesn't change after fault and it continues to generate a positive sequence voltage with frequency of $s \omega$. Now, according to eq. (11) we see that the rotor current will contain a complex current waveform that has a transient term, too. The rectified form of this current has to pass through superconductor DC reactor; therefore, the DC reactor prevents rapid increasing of all frequencies and transient term of fault current in rotor circuit. It also increases the voltage drop and results in decreasing the imposed voltage on the RSC. These functions improve the ability of DFIG to FRT without losing current controllability as well as preventing the RSC from the damage.

\section{SimULATION RESULTS}

The operation of DFIG based wind turbine with the proposed FCL is simulated by PSCAD/EMTDC software. Fig. 4 shows the single line diagram of the test system. 


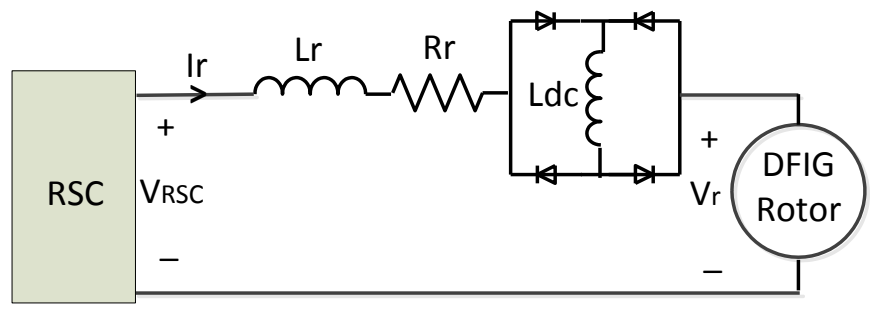

Fig. 3. Single-phase modelling of proposed diode bridge SFCL in rotor circuit of DFIG

The simulation parameters are given in table I. Fig. 4 shows the fault location in the simulated system. A three phase to ground (LLLG) fault has applied at $\mathrm{t}=2(\mathrm{sec})$ and it is cleared at $2.3(\mathrm{sec})$. Fig. 5 shows selected simulation results and compares the results with and without the proposed FCL.

Fig. 5 from top to down shows the simulation results for stator voltages, stator currents, rotor currents, rotor voltages, DC capacitor voltage, angular speed of rotor and electric and mechanical output torque from the rotor.

During the fault, the stator voltage has experienced $15 \%$ symmetrical voltage dip. Simulation results for stator currents show that the SFCL has not had considerable effect on stator currents.

Comparison of results with and without using SFCL for rotor currents shows that the SFCL has had significant role in reduction of rotor currents during fault condition. This figure shows that the peak of the transient current in the rotor circuit $\left(\mathrm{I}_{\mathrm{rabc}}\right)$ has decreased from $2.9(\mathrm{pu})$ to $1.8(\mathrm{pu})$ just after the fault and it has decreased from 2.3 (pu) to 2 (p.u) after the fault clearing at $2.3(\mathrm{sec})$.

Obviously, the proposed SFCL will not have considerable effect on induced voltage in the rotor. By considering this fact that the proposed FCL is a superconducting type, it will not have considerable effect on DC side voltage reduction, because it doesn't dissipates power; so, the energy from rotor circuit will pass through the SFCL and RSC toward the DC capacitor and will continue charging the capacitor irrespective of the presence of SFCL in the circuit. Because the speed change and torque of wind turbine depend on the active power in the wind turbine and SFCL does not have any impact on this, the mentioned parameters will not be affected by the proposed SFCL during the fault.

\section{CONCLUSION}

This paper has proposed an application of a three phase diode bridge type SFCL in the rotor circuit of DFIG based wind turbines. The results demonstrate that the fault ridethrough capability of the DFIG is improved by using the proposed diode-bridge SFCL. The diode-bridge SFCL has limited the rotor current during fault condition without any considerable effect on any other parameters of wind turbine such as stator currents, rotor voltage, DC link capacitor voltage, rotor angular speed and electrical and mechanical torques from rotor during fault. The limitation of fault current comes into effect during fault condition whereas the proposed system doesn't pose any effect on DFIG operation during normal operation. The SFCL doesn't need any control or measurement circuit. Analytical analysis during normal operation as well as fault condition are presented. The single phase model of the proposed SFCL is used for analysis of its performance. Simulation results prove that the proposed diode-bridge SFCL is capable to limit the fault current and improve LVRT of the DFIG wind turbines..

;

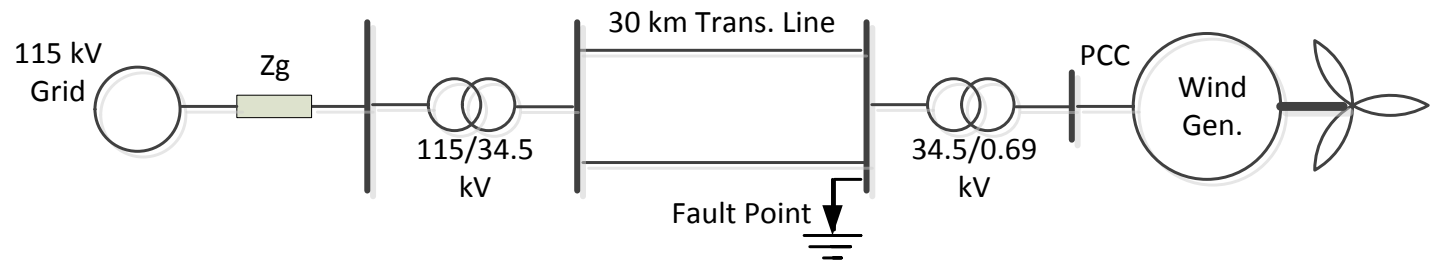

Fig. 4. Single line diagram of test system

Table I: Simulation parameters

\begin{tabular}{|lr|lr|lr|}
\hline \multicolumn{2}{|c|}{ System data } & \multicolumn{2}{c|}{ Generator data } & \multicolumn{2}{c|}{ Other data } \\
\hline Base Power: & $10 \mathrm{MVA}$ & Rated Power: & $2 \mathrm{MW}$ & Rated dc-link voltage: & $1200 \mathrm{~V}$ \\
Base voltage at generator & & Rated Stator Voltage: & $690 \mathrm{~V}$ & DC bus capacitor: & $50 \mathrm{mF}$ \\
terminals: & $690 \mathrm{~V}$ & Stator leakage inductance: & $0.12 \mathrm{pu}$ & Nominal wind speed: & $13 \mathrm{~m} / \mathrm{s}$ \\
Base Frequency: & $60 \mathrm{~Hz}$ & Rotor leakage inductance: & $0.12 \mathrm{pu}$ & Transmission line resistance $0.5 \Omega$ \\
& & Magnetizing Inductance: & $3.45 \mathrm{pu}$ & Transmission line inductance $0.2 \mathrm{H}$ \\
& & Stator to Rotor turns ratio: 0.35 & Source resistance & $0.5 \Omega$ \\
& & Stator resistance: $r 0.011 \mathrm{pu}$ & Source inductance & $0.2 \mathrm{H}$ \\
& & Stator inductance: & $0.012 \mathrm{pu}$ & SFCL DC inductance & $45 \mathrm{mH}$ \\
& & \multicolumn{2}{|c|}{ Generator inertia constant: $0.85 \mathrm{~s}$} & & \\
\hline
\end{tabular}




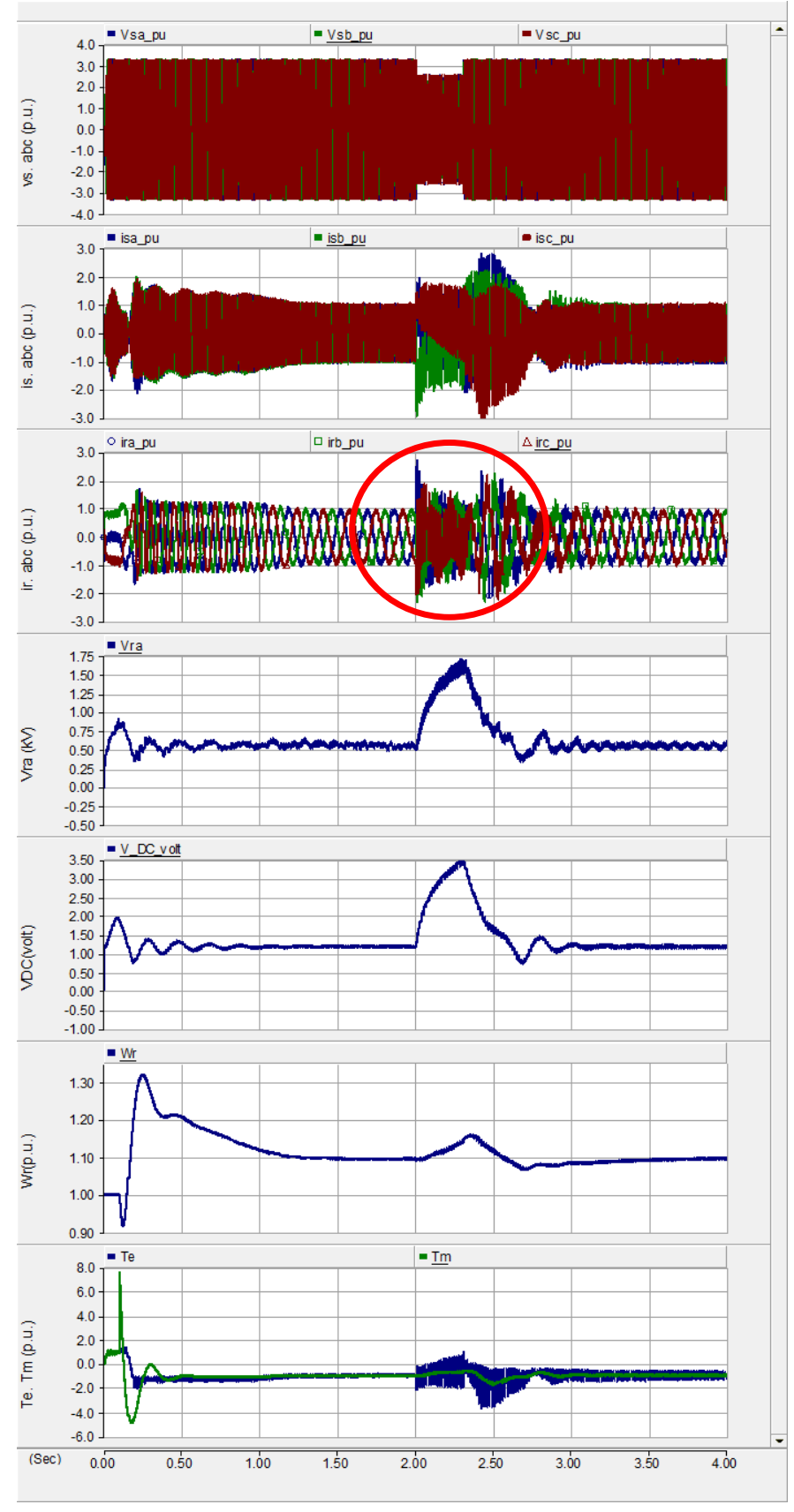

(a) Without FCL

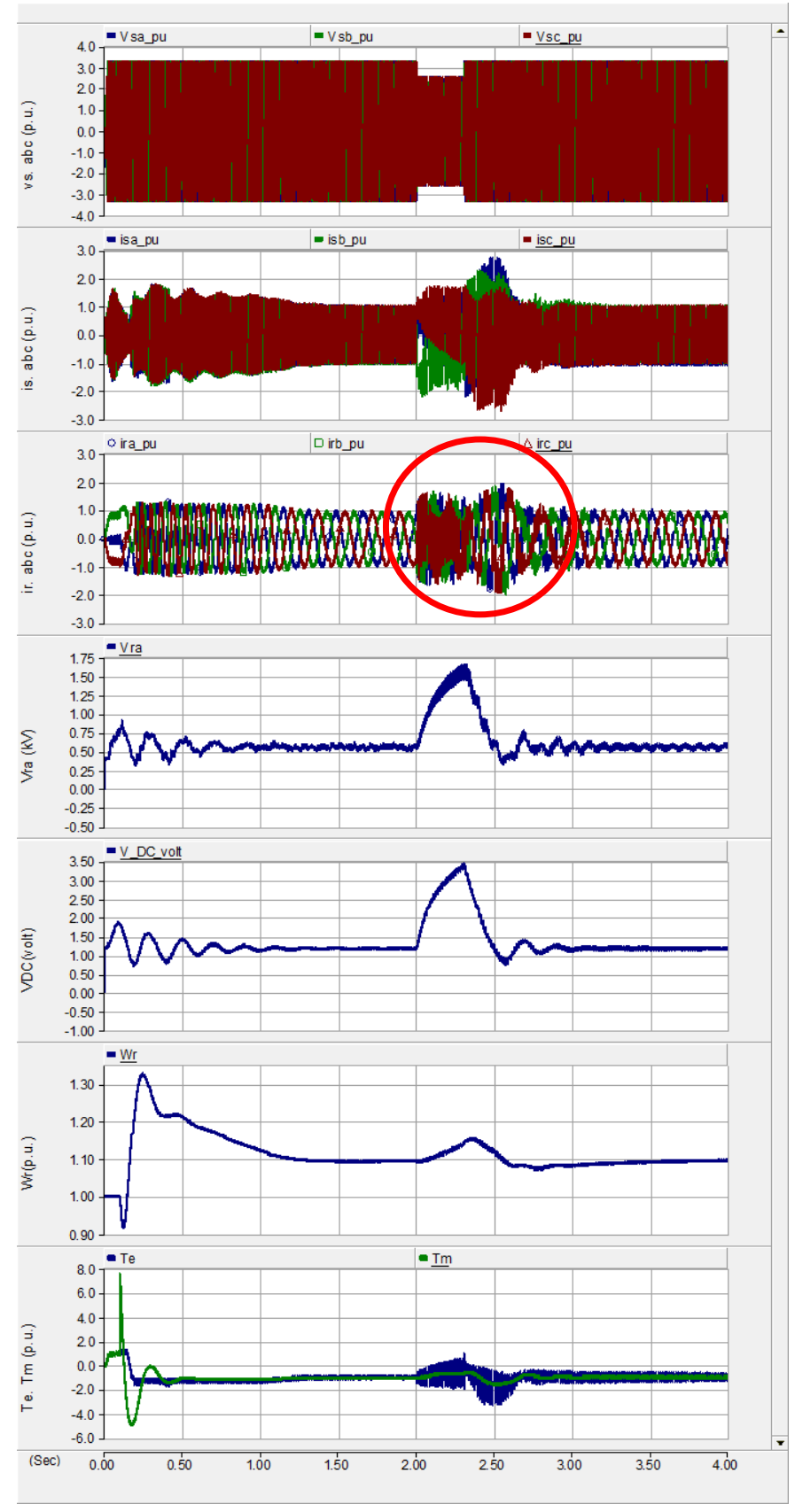

(b) By using the proposed FCL

From top to bottom: Vsabc_pu, isabc_pu, irabc_pu, Vra (kV), V_DC (kV), $\omega r(\mathrm{pu}), \mathrm{Te}, \mathrm{Tm}(\mathrm{pu})$

Fig. 5. Simulation results for a LLLG fault occurred at $t=2 \mathrm{sec}$. for a duration of $0.3 \mathrm{msec}$

\section{REFERENCES}

[1] Bharat Singh and S.N. Singh, "Wind Power Interconnection into the Power System: A Review of Grid Code Requirements", Elsevier, The Electricity Journal, Vol. 22, Issue 5, June 2009, pp. 54-63.

[2] Y. Yang; P. Enjeti, F. Blaabjerg, H. Wang, "Suggested grid code modifications to ensure wide-scale adoption of photovoltaic energy in distributed power generation systems", IEEE Industry Applications Society Annual Meeting, Florida, Oct. 2013.

[3] N.K. Roy, H.R. Pota, "Current Status and Issues of Concern for the Integration of Distributed Generation into Electricity Networks", IEEE Systems journal, Issue 99, 2014, to be published.
[4] Australian Energy Market Operator (AEMO), "Wind Integration: International Experience, WP2: Review of Grid Codes", 2nd October 2011.

[5] "ENTSO-E Network Code for Requirements for Grid Connection Applicable to all Generators", 8 March 2013.

[6] L. Rouco, K. Chan, J. Oesterheld, S. Keller, "Recent Evolution of European Grid Code Requirements and its Impact on Turbogenerator Design", IEEE Power and Energy Society General Meeting, 22-26 July, 2012 . 
[7] T. Preda, K. Uhlen, D. Nordgard, "An Overview of the Present Grid Codes for Integration of Distributed Generation", CIRED Workshop Lisbon, 29-30 May, 2012, paper 0020

[8] M. Tarafdar Hagh, M. Abapour, "Non-superconducting Fault Current Limiter with Controlling the Magnitudes of Fault Currents", IEEE Transactions on Power Electronics, Vol. 24, No. 3, March 2009, pp. 613 619.

[9] M. Tarafdar Hagh, M. Abapour , "Non-Superconducting Fault Current Limiters", European Transactions on Electrical Power, Vol. 19, Issue 5, July 2009, pp. 669-682.

[10]M. Tarafdar Hagh, S. Behzad Naderi, M. Jafari, "Using Nonsuperconducting Fault Current Limiter as Inrush Current Limiter", ELECO 2011, 7th Intl. Conf. on Elect. and Electronics Eng., 1-4 Dec. 2011, Bursa, Turkey, Paper ID: 134, pp. 269-273.

[11]M. Tarafdar Hagh; M. Jafari; S. B. Naderi, "Application of Nonsuperconducting Fault Current Limiter to Improve Transient Stability", 2010 IEEE Intl .Conf. on Power and Energy (PECon 2010), 29 Nov.-1 Dec., 2010, Kuala Lumpur, Malaysia, Paper on CD.

[12] A. Charmin, M. Tarafdar Haque, M. Abapour, "Non-Superconducting Fault Current Limiter", Intl. Conf. on Application of Electrical Eng., 1214 March. 2006, Prague, Check Republic, pp. 12-17.

[13] A. R. Fereidouni, B. Vahidi, T. Hosseini Mehr, "The Impact of Solid State Fault Current Limiter on Power Network With Wind-Turbine Power Generation," IEEE Transactions on Smart Grid, Vol. 4, No. 2, June 2013, pp. 1188-1196.
[14]S. Alaraifi, A. Moawwad, M. S. El Moursi, V. Khadkikar, "Voltage Booster Schemes for Fault Ride-Through Enhancement of Variable Speed Wind Turbines," IEEE Transactions on Sustainable Energy, Vol. 4, No. 4, October 2013, pp. 1071-1081.

[15]M. Firouzi and G. B. Gharehpetian, "Improving Fault Ride-Through Capability of Fixed-Speed Wind Turbine by Using Bridge-Type Fault Current Limiter," IEEE Transactions on Energy Conversion, Vol. 28, No. 2, June 2013, pp. 361-369.

[16] G. Rashid, M. Hasan Ali, A Modified Bridge-Type Fault Current Limiter for Fault Ride-Through Capacity Enhancement of Fixed Speed Wind Generator," IEEE Transactions on Energy Conversion, Vol. 29, No. 2 , June 2014, pp. 527-534.

[17] Wenyong Guo, Liye Xiao, and Shaotao Dai, "Enhancing Low-Voltage Ride-Through Capability and Smoothing Output Power of DFIG With a Superconducting Fault-Current Limiter-Magnetic Energy Storage System," IEEE Transactions on Energy Conversion, Vol. 27, No. 2, June 2012, pp. 277-295.

[18]Hua Geng, Cong Liu, Geng Yang, "LVRT Capability of DFIG-Based WECS Under Asymmetrical Grid Fault Condition", IEEE Transactions On Industrial Electronics, Vol. 60, No. 6, June 2013, pp. 2495-2509.

[19] Huang Qingjun, Sun Mucun,Zou Xudong, Tong Li, Xiong Wei,Chen Jianqing, "A Reverse Current Tracking Based LVRT Strategy for Doubly Fed Induction Generator (DFIG)," Industrial Electronics Society, IECON 2013 - 39th Annual Conference of the IEEE , pp. 72957300 . 